\title{
Children exposed to second hand-smoke and sensorineural hearing loss
}

\begin{abstract}
Background: Smoking is considered one of most common habits among the world's population. Second-hand smoke (SHS) is a vital public health problem. As there are multiple intrinsic and extrinsic factors for hearing loss, the second-hand smoke (SHS) is considered one of these factors. As agreed to the serious adversative health impacts of second-hand smoke there is a global care about childhood environmental tobacco smoke exposure. A correlation between passive smoking and hearing loss in infants, children, adolescents, and adults had been reported by many studies.
\end{abstract}

Aim: To evaluate the effect of second-hand smoke exposure during childhood on the peripheral auditory system.

Patient and methods: This study includes 50 apparently healthy children (100 ears) and 50 children that exposed to second- hand smoking (100 ears). The range of their age was between 6-12 years. All children subjected to history taking, otological examination, basic audiological evaluation and TEOAE.

Results: There was statistically significant difference was found between study and control groups as regard pure tone threshold at a frequency range $(500-4000 \mathrm{~Hz})$ and also there was a difference in $\mathrm{S} / \mathrm{N}$ ratio of TEOAE at all frequency bands, but still the both within the normal range in the study group.

Conclusion: The negative effects of smoking on the hearing can occur even after a short period of exposure to smoke. TEOAEs appear to be the early indicator of cochlear affection by smoke.

Keywords: second-hand smoke, children, OAE, SNHL
Volume II Issue I - 2019

\author{
Reem Elbeltagy,' Dalia Galhom,' Marwa Abd \\ El-Hafeez ${ }^{2}$ \\ 'Lecturer of Audiovestibular Medicine, ENT Department, \\ Faculty of Medicine, Zagazig University, Egypt \\ ${ }^{2}$ Lecturer of ENT, ENT Department, Faculty of Medicine, Minia \\ University, Egypt
}

Correspondence: Reem Elbeltagy, Lecturer of Audiovestibular Medicine, ENT Department, Faculty of Medicine, Zagazig University, Zagazig, El Sharkia, Egypt, Tel 0I019763 I344, Email Reem.elbeltagy@yahoo.com

Received: December 14, 2018 | Published: January 04, 2019

\section{Introduction}

Smoking is considered one of most common habits among the world's population. ${ }^{1}$ Second-hand smoke (SHS) is a vital public health problem. It is difficult to determine the safe level of tobacco exposure. Parents' smoking is considered the main cause of SHS in children. About $30 \%$ of children lived with at least one smoker in their family either mother or father and about $60 \%$ of them exposed to environmental smoke (secondhand smoke) (SHS). There are different conditions that affect exposure rates like sex, age, culture and socioeconomic condition of the family. ${ }^{2}$

A previous study concludes that there is a correlation between prenatal smoking and low birth weight, ${ }^{3}$ cognitive and behavioral changes. ${ }^{4-5}$ Immune system change,${ }^{6}$ interference with normal utero development, ${ }^{7}$ and a change in hemodynamic, ${ }^{8}$ all may be explained the side effect associated with prenatal SHS.

It was proved that SHS could affect the auditory system in different ways. According to a study conducted in united states, about $60 \%$ of children exposed to SHS are at high risk of otitis media ${ }^{9}$ due to suppression of the immune system, bacterial adherence factors enhancement, and impairment of the respiratory mucociliary function that result in Eustachian tube dysfunction. ${ }^{6}$ In addition, the harmful effects of smoking on the hearing may resemble that of noise and it may disturb the recovery mechanism in the cochlear hair cell loss was reported to occur. ${ }^{10}$ Second-hand smoker at high risk of hearing loss; exposure to environmental smoke was associated with a 4.9 times increase in the prevalence of hearing deficits. ${ }^{11}$ Also, the incidence of low-frequency hearing in the second-hand smoke is higher than the non-exposed person. ${ }^{12-13}$ This could be explained due to smoking may decrease oxygen and increase blood viscosity that leads to damage to cochlear hair cell. ${ }^{14}$

The objective of the present study was to evaluate the effect of second-hand smoke exposure during childhood on the peripheral auditory system.

\section{Methods}

\section{Study design $\&$ subjects}

This study was a comparative case-control study. A total number of 100 children: 50 apparently healthy children (100 ears) and 50 children that exposed to second-hand smoking (100 ears). The range of their age was between 6-12 years. The study was conducted on the audio-vestibular unit, Ear Nose and Throat Departments of Zagazig University Hospitals.

\section{Ethical considerations}

In the present study, all the testing procedures were performed using non-invasive techniques. The history sheet and consent form were given to their parents before children participate in the study.

Inclusion criteria the inclusion criteria were: (i) normal speech and language (ii) absence of any disease or condition that may cause sensorineural hearing loss and (iii) normal middle ear function on the day of hearing assessment. They were divided into 2 groups according to the exposure to smoking (case and control). 


\section{Audiological evaluation}

A. History taking: Full history taking including personal history, history of hearing loss, tinnitus, discharge, earache, headache or vertigo, past history of systemic disease, physical trauma, ototoxic drug or previous operations and family history. The parents were asked about the permission of smoking in the home in the presence of the children.

B. Otological examination: pre-auricular region, ear pinna, postauricular region, external acoustic: auditory canal, \& tympanic membrane.

\section{Basic audiological evaluation:}

a. Pure-tone audiometry using orbiter 922 (GM Otomtrix, Denmark): This included Air conduction ( Air conduction hearing thresholds were determined by frequency range 0.250 and $8 \mathrm{~K} \mathrm{~Hz}$ ) and Bone-conduction (bone conduction hearing thresholds were determined by frequency range 0.500 and $4 \mathrm{~K}$ $\mathrm{Hz}$. Hearing thresholds greater than $20 \mathrm{~dB}$ were considered as HL.

b. Speech audiometry (Speech Reception Threshold (SRT) using Arabic spondee words and the Word discrimination scores (WDS) using Arabic phonetically balanced words.

c. Immittancemetry using Amplaid 724 (Amplifon, Italy). This included tympanometry and acoustic reflex threshold measurement.

D. Otoacoustic emission: The TEOAEs were elicited using the ILO 292 device (Otodynamics Ltd., Hatfield, UK). TEOAEs were recorded using the nonlinear protocol, stimulus levels were kept at the standard default settings click stimulus and the stimulus intensity ranged between $80-90 \mathrm{~dB}$, the recording window was 20 $\mathrm{ms}$, and A total of 260 sweeps were averaged using a $500-6000 \mathrm{~Hz}$ bandpass filter. The TEOAEs measurements were made in each ear, stimuli were presented to the subject through a miniature transducer housed in a probe fitted in the individual external ear canal. The stimulus level in the ear canal was measured using a miniature microphone also housed within the probe. The level of TEOAE was automatically determined in 5 octave bands $(1,1.4$, 2, 2.8, and $4 \mathrm{kHz}$ ).

OAE SNRs and response levels were used for analyses. A response was considered as present whenever there was an emission of at least $3 \mathrm{~dB}$ above the noise floor at any tested frequency band. Accordingly, the results of TEOAE were interrupted into one of three categories: pass (significant response in all bands), partial pass (significant response in some bands) and fail (no significant response in any of the frequency bands).

\section{Statistical analysis}

Data were analyzed by the Statistical Package of Social Science (SPSS), software version 24.0 (SPSS Inc., 2016). Continuous variables were presented as the Mean \pm SD or Median (Range). Categorical variables were presented by the count and percentage. Independentsamples t-test is used to determine if a difference exists between the means of two independent groups on a continuous dependent variable. Chi-squared test of association is used to discover if there is a relationship between two categorical variables. The differences were considered significant at $\mathrm{P}<.05$. All statistical comparisons were two-tailed.

\section{Results}

\section{Baseline characteristics of the control and study groups}

Ages ranged between 6 and 12 years with a mean age of control group $8.4 \pm 1.2$ and $8.9 \pm 1.5$ of the study group. They were 22 females (44\%) and 28 males (56\%) in the control group and in the study group was 20 females $(40 \%)$ and 30 males (60\%). Baseline characteristics (age and sex) were similar between the control and patients groups $(\mathrm{P}>.05)$ as shown in Table 1.

Table I Baseline characteristics of the control and study groups

\begin{tabular}{|c|c|c|c|c|c|c|}
\hline \multirow[b]{2}{*}{ Variable } & \multicolumn{2}{|l|}{ Control } & \multicolumn{3}{|l|}{ Study } & \multirow[b]{2}{*}{$\mathbf{p}$} \\
\hline & Mean & \pm SD & Mean & \pm SD & Test of significance & \\
\hline Age & 8.4 & 1.2 & 8.9 & 1.5 & $\mathrm{t}=1.42$ & 0.159 \\
\hline \multicolumn{7}{|l|}{ Sex } \\
\hline $\begin{array}{l}\text { Females } \\
\text { Males }\end{array}$ & $\begin{array}{l}22(44 \%) \\
28(56 \%)\end{array}$ & & $\begin{array}{l}20(40 \%) \\
30(60 \%)\end{array}$ & & $x^{2}=0.16$ & 0.685 \\
\hline
\end{tabular}

$x^{2}$, Chi-squared test

The distribution of the study group according to presence and absence of hearing loss. The percentage of hearing loss in SHS was $20 \%$, (8\% bilateral and $12 \%$ unilateral). The hearing threshold was affected in the frequency range between 500 to $4000 \mathrm{~Hz}$ (Table 2) (Table 3).

Table $\mathbf{2}$ The distribution of study group according to presence and absence of hearing loss

\begin{tabular}{lll}
\hline & N. of SHS & $\%$ \\
\hline Total \% of HL & 10 & $20 \%$ \\
Bilateral & 4 & $8 \%$ \\
Unilateral & 6 & $12 \%$ \\
\hline Normal hearing & 40 & $80 \%$
\end{tabular}

Table 3 Mean, Standard deviation (SD) and range of pure tone thresholds in $\mathrm{dB} H \mathrm{H}$ in 14 ears of the study group

\begin{tabular}{llll}
\hline Frequency $(\mathbf{H z})$ & Mean & $\underline{\mathbf{X S D}}$ & Range \\
\hline 250 & 16.2 & 2.9 & $10-20$ \\
500 & 30.3 & 1.8 & $20-35$ \\
1000 & 32.1 & 6.1 & $20-45$ \\
2000 & 33.2 & 4.8 & $30-45$ \\
4000 & 35 & 7.3 & $25-45$ \\
8000 & 11.7 & 3 & $5-15$ \\
\hline
\end{tabular}




\section{Pure tone thresholds in study and control group}

Table 4 shows Mean Standard deviation (SD) of pure tone thresholds in $\mathrm{dB}$ HL in 100 years of the study group and 100 ears of the control group. There was a statistically significant difference between 2 groups in pure tone threshold at 500,1000, 2000 and $4000 \mathrm{~Hz}$ as it is higher in the study group, but it is still in the normal hearing sensitivity range.

Table 4 Mean, Standard deviation (SD) of pure tone thresholds in $\mathrm{dB}$ HL in 100 ears of the study group and 100 ears of the control group

\begin{tabular}{lllllll}
\hline \multirow{2}{*}{ Frequency $(\mathbf{H z})$} & \multicolumn{7}{c}{ Control } & \multicolumn{7}{c}{ Study } & & \\
\cline { 2 - 6 } & Mean & +SD & Mean & +SD & t & P \\
\hline 250 & 11.5 & 3.7 & 12.3 & 2.5 & 0.00 & 1.00 \\
500 & 13.1 & 2.1 & 13.3 & 2.4 & 2.91 & $0.004^{*}$ \\
1000 & 14.5 & 1.3 & 16.8 & 9.7 & 2.3 & $0.019^{*}$ \\
2000 & 12.3 & 2.2 & 15.2 & 9.4 & 3 & $0.003^{*}$ \\
4000 & 12.5 & 2.6 & 14.6 & 7.8 & 2.5 & $0.01 I^{*}$ \\
8000 & 14.8 & 1.8 & 15.1 & 1.5 & 0.99 & 0.323 \\
\hline
\end{tabular}

$\mathrm{P} \geq 0.05$, nonsignificant. $* \mathrm{P}<0.05$, significant.

TEOAE in control (100 ears) and study group (100 ears). In the current study, 64 ears of the study group had a total pass, on the other hand, there were $30 \%$ with a partial pass and $6 \%$ with failed TEOAE (Table 5).

Table 6 shows statistically significant difference was found in S/N ratio of TEOAE between study and control groups at all frequency bands, as it is less in the study group, but it is still normal signal to noise ratio.
Table 5 Distribution of otoacoustic emission in SHS children (100 ears)

\begin{tabular}{ll}
\hline OAE & Number of ears (\%) \\
\hline Pass & $64(64 \%)$ \\
Partial pass & $30(30 \%)$ \\
Fail & $6(6 \%)$ \\
\hline
\end{tabular}

Table 6 Mean and Standard deviation (SD) of the signal to noise(S/N) ratio of TEOAE in control ( 100 ears) and study group (I00 ears)

\begin{tabular}{|c|c|c|c|c|c|c|}
\hline \multirow{2}{*}{$\begin{array}{l}\text { Frequency } \\
(\mathrm{Hz})\end{array}$} & \multicolumn{2}{|c|}{ Control } & \multicolumn{2}{|l|}{ Study } & \multirow{2}{*}{$\mathbf{t}$} & \multirow{2}{*}{$\mathbf{P}$} \\
\hline & Mean & +SD & Mean & $+\mathrm{SD}$ & & \\
\hline 1000 & 12.5 & 3.1 & 11.3 & 2.2 & 2.44 & $0.016 *$ \\
\hline 1400 & 16.1 & 2.5 & 15 & 3.1 & 2.13 & $0.034 *$ \\
\hline 2000 & 15.9 & 2.1 & 14.8 & 2.9 & 2.37 & $0.018 *$ \\
\hline 2800 & 17.3 & 4.3 & 15.9 & 3.7 & 2.46 & $0.014 *$ \\
\hline 4000 & 14.3 & 3.3 & 13.1 & 2.5 & 2.89 & $0.004 *$ \\
\hline
\end{tabular}

$\mathrm{P} \geq 0.05$ : Nonsignificant. $* \mathrm{P}<0.05$ : significant.

\section{Discussion}

There are multiple intrinsic and extrinsic factors for hearing loss; the second-hand smoke (SHS) is considered one of these factors. As agreed to the serious adversative health impacts of second-hand smoke, there is a global care about childhood environmental tobacco smoke exposure. ${ }^{15} \mathrm{~A}$ correlation between passive smoking and hearing loss in infants, children, adolescents, and adults had been reported by many studies.

In this study, ages ranged between 6 and 12 years with a mean age of control group $8.9 \pm 1.5$ and $8.4 \pm 1.2$ of the study group. The children involved in this study were ( $40 \%$ females, $60 \%$ males for the study group \& $44 \%$ females, $56 \%$ males for the control group). Baseline characteristics were similar between the control and study groups (Table 1).

In the present study, $20 \%$ of SHS children showed an elevation in their hearing threshold ( $8 \%$ bilateral, $12 \%$ unilateral); the hearing threshold was affected in the frequency range between 500 to $4000 \mathrm{~Hz}$ (Table 2) (Table 3). Also, there was a statistically significant difference between the SHS group and the control group in pure tone threshold at $500,1000,2000 ; 4000 \mathrm{~Hz}$ (Table 4). This result was in accordance with Lalwani AK et al. that established a relation between SHS and elevated pure-tone thresholds, this relation was statistically significant at 2,3 , and $4 \mathrm{kHz} \cdot{ }^{16}$ Also, Fabry et al., ${ }^{17}$ reported that the exposure to second-hand smoke led to hearing loss in all frequencies. In addition, the study conducted by Ohgami et al. ${ }^{18}$ that reported the consequence of smoking on extra-high frequency pure tone thresholds and proved that the pure tone thresholds of smoker group were considerably worse than non-smokers especially at $12 \mathrm{kHz} .{ }^{18}$

The increased risk of hearing loss is relevant to SHS exposure, which recently has been established to be an important determinant for the development of hearing loss between adolescents 12 to 19 years old as evidenced by Lalwani AK et al. ${ }^{16}$ Children exposed to SHS at high risk to develop unilateral hearing loss, with continued 
exposure hearing loss could progress to be bilateral and also, other frequencies may be affected. ${ }^{16}$

The exact ototoxic mechanism of smoking is not clear. It has been suggested that smoking might be harmful to the cochlea due to either a direct nicotine ototoxic effect, hypoxemia or vascular ischemia in the cochlea as a result of vasoconstriction, vasospasm, production of carboxyhemoglobin, increased blood viscosity, or arteriosclerosis of blood vessels. ${ }^{19}$ Also, the auditory function is affected by oxidative stress produced by smoking. ${ }^{20-21}$ An earlier study found in the cochlear hair cells nicotinic-like receptors, which may propose that tobacco smoke has harmful effects on the function of the hair cell, especially through the auditory neurotransmission. ${ }^{22}$ Moreover, the smoking could be combined with other risk factors of hearing loss as noise causing synergistic harmful effects on the auditory system. ${ }^{20-23-24}$

Several studies reported an association between SHS and loss of hearing prenatally, and in the infantile period, childhood, and adolescents. ${ }^{25-26}$ The reduction of the cochlear physiology during all period of childhood which is a serious period of the development of hearing abilities might lead to a progressive disorder of the auditory system. ${ }^{25}$ Key et al., ${ }^{13}$ reported that maternal smoking can affect normal fetal brain development causing auditory cognitive dysfunction.

SHS exposure in childhood is proposed to affect the physiology of the cochlea by distressing the outer hair cells which can be accessed through a decreased in (TEOAE) response. ${ }^{25}$ In the current study, 64 ears of the study group had a total pass; on the other hand, there were $30 \%$ with a partial pass and $6 \%$ with failed TEOAE (Table 5). Moreover, TEOAEs showed lower signal to noise ratios (SNRs) at all frequency bands when the SHS group was compared to the control group (Table 6). This agreed with Durante et al., ${ }^{25}$ that found a lower response level of TEOAEs, mainly at frequencies of $2-2.8 \mathrm{kHz}$, and also lower signal to noise ratios (SNRs), mainly at $1-1.4 \mathrm{kHz}$, in the children with SHS when compared to the non-exposed one. Also, Paschoal \& Azevedo ${ }^{27}$ stated that the reduction in TEOAEs was found at $1 \mathrm{kHz}$, similar to the present study. It was considered an emerging evidence of the impacts of nicotine toxicity and an association between smoking and hearing loss, and continued exposure to smoking could cause hearing loss.

\section{Conclusion}

To conclude, the negative effects of smoking on the hearing can occur even after a short period of exposure to smoke. TEOAEs appear to be the early indicator of cochlear affection by smoke. Parents' awareness about the impact of SHS on children, the risk of hearing loss and cognitive function is highly recommended. Also, a routine complete audiological evaluation must be performed for all children that exposed to smoking for early diagnosis and management of hearing loss.

\section{Funding}

This research did not receive any specific grant from any funding agency in the public, commercial or not for profit sector.

\section{Acknowledgements}

The authors appreciate the assistance of all children who participated in this work.

\section{Conflict of interest}

Authors declare that there is no conflict of interest.

\section{References}

1. Yolton K, Dietrich K, Auinger P, et al. Exposure to environmental tobacco smoke and cognitive abilities among U.S. children and adolescents. Environ Health Perspect. 2005;113(1):98-103.

2. Hofhuis W, de Jongste JC, Merkus PJ. Adverse health effects of prenatal and postnatal tobacco smoke exposure on children. Arch Dis Child. 2003;88(12):1086-1090.

3. Mathews TJ, Menacker F, MacDorman MF. Infant mortality statistics from the 2002 period: linked birth/infant death data set. Natl Vital Stat Rep. 2004;53(10):1-29.

4. Ernst M, Moolchan ET, Robinson ML. Behavioral and neural consequences of prenatal exposure to nicotine. $\mathrm{J} \mathrm{Am} \mathrm{Acad} \mathrm{Child} \mathrm{Adolesc}$ Psychiatry. 2001;40 (6):630-641.

5. Gehrman CA, Hovell MF. Protecting children from environmental tobacco smoke (ETS) exposure: a critical review. Nicotine Tob Res. 2003;5(3):289-301.

6. Torp-Pedersen T, Boyd HA, Poulsen G, et al. In-utero exposure to smoking, alcohol, coffee, and tea and risk of strabismus. Am J Epidemiol. 2010;171(8):868-875.

7. Marseglia GL, Avanzini MA, Caimmi S, et al. Passive exposure to smoke results in defective interferon-gamma production by adenoids in children with recurrent respiratory infections. J Interferon Cytokine Res. 2009;29(8):427-432.

8. Duncan JR, Garland M, Myers MM, et al. Prenatal nicotine-exposure alters fetal autonomic activity and medullary neurotransmitter receptors: implications for sudden infant death syndrome. $J$ Appl Physiol. 2009;107(5):1579-1590.

9. Thornton AJ, Lee PN. Parental smoking and middle ear disease in children: a review of the evidence. Indoor Built Environ. 1999;8(1):2139.

10. Ahn JH, Joo HS, Suh JK, et al. Effects of cigarette smoking on hearing recovery from noise-induced temporary hearing threshold shifts in mice. Otol Neurotol. 2011;32(6):926-932.

11. Lyons RA. Passive smoking and hearing loss in infants. Ir Med J. 1992;85(3):111-112.

12. Jacobsen LK, Slotkin TA, Mencl WE, et al. Gender-specific effects of prenatal and adolescent exposure to tobacco smoke on auditory and visual attention. Neuropsychopharmacology. 2007;32(12):2453-2464.

13. Key AP, Ferguson M, Molfese DL, et al. Smoking during pregnancy affects speech-processing ability in newborn infants. Environ Health Perspect. 2007;115(4):623-629.

14. Fransen E, Topsakal V, Hendrickx J, et al. Occupational noise, smoking, and a high body mass index are risk factors for age-related hearing impairment and moderate alcohol consumption is protective: A European population-based multicenter study. J Assoc Res Otolaryngol. 2008;9(3):264-276.

15. World Health Organization, \& Tobacco Free Initiative. Protection from exposure to second-hand tobacco smoke: policy recommendations. World Health Organization. 2007.

16. Lalwani AK, Liu YH, Weitzman M. Secondhand smoke and sensorineural hearing loss in adolescents. Arch Otolaryngol Head Neck Surg. 2011;137(7):655-662.

17. Fabry DA, Davila EP, Arheart KL, et al. Secondhand smoke exposure and the risk of hearing loss. Tob Control. 2011;20(1):82-85.

18. Ohgami N, Kondo T, Kato M. Effects of light smoking on extra-highfrequency auditory thresholds in young adults. Toxicol Ind Health. 2011;27(2):143-147. 
19. Barone JA, Peters JM, Garabrant DH, et al. Smoking as a risk factor in noise-induced hearing loss. J Occup Med. 1987;29(9):741-745.

20. Yamasoba T, Lin FR, Someya S, et al. Current concepts in age-related hearing loss: epidemiology and mechanistic pathways. Hear Res. 2013;303:30-38.

21. Ortigosa SM, Diaz-Vivancos P, Clemente-Moreno MJ, et al. Oxidative stress induced in tobacco leaves by chloroplast over-expression of maize plastidial transglutaminase. Planta Med. 2010;232(3):593-605.

22. Elgoyhen AB, Katz E, Fuchs PA. The nicotinic receptor of cochlear hair cells: a possible pharmacotherapeutic target? Biochem Pharmacol. 2009;78(7):712-719

23. Cruickshanks KJ, Nondahl DM, Dalton DS, et al. Smoking, central adiposity, and poor glycemic control increase risk of hearing impairment. J Am Geriatr Soc. 2015;63(5):918-924.
24. Wild DC, Brewster MJ, Banerjee AR. Noise-induced hearing loss is exacerbated by long-term smoking. Clin Otolaryngol. 2005;30(6):517520.

25. Durante AS, Pucci B, Gudayol N, et al. Tobacco smoke exposure during childhood: effect on cochlear physiology. Int $J$ Environ Res Public Health. 2013;10(11):5257-5265.

26. Weitzman M, Govil N, Liu YH, et al. Maternal prenatal smoking and hearing loss among adolescents. JAMA Otolaryngol Head Neck Surg. 2013;139(7):669-677.

27. Paschoal CP, Azevedo MF. Cigarette smoking as a risk factor for auditory problems. Braz J Otorhinolaryngol. 2009;75(6):893-902. 